\title{
Phase Analysis of the Data Dynamics from the Tourism Sector
}

\author{
Vyacheslav Lyashenko \\ lyashenko.vyacheslav@gmail.com \\ Department of Informatics, Kharkiv National University of RadioElectronics, Ukraine \\ Received: October 24, 2020 \\ Revised: October 31, 2020 \\ Accepted: November 2, 2020
}

\begin{abstract}
The tourism industry covers various areas of economic activity. Tourism has various areas and directions of its implementation. One of the significant areas of tourism is international tourism. International tourism influences and reflects different spheres of human economic activity. This type of economic activity can have a non-linear nature of the processes that describe it. To analyze and identify such processes, the concept of a phase portrait is used. The paper reveals the features of nonlinear dynamics of processes in the field of tourism. We used real data to construct individual phase portraits in the tourism sector. A number of specific examples of the analysis of indicators from the tourism sector are given.
\end{abstract}

Keywords: International Tourism, Phase Portrait, Tourism Income, Tourism Expenditure

\section{Introduction}

The tourism sector is one of the areas of economic activity. Tourism is associated with the travel of people (Butcher, 2019; Pencarelli, 2020; McKercher \& Mak, 2019). Therefore, tourism covers various areas of human activity. Also, the tourism sector affects various areas of economic activity. Thus, the tourism sector can be considered as one of the factors of economic development. The tourism sector has different classifications (Hashimli, 2019; Alimova et al., 2020). International tourism is one of the directions of tourism development. International tourism contributes to the development of international trade, international development, international communication, economic development. This makes it important to consider data that reveal the dynamics of the tourism sector.

Various methods and approaches can be used to study the dynamics of tourism data (Xu et al., 2020; Akadiri et al., 2020; Baranova, 2020). These methods and approaches allow for simple and complex data analysis. This analysis allows us to investigate the current state of the tourism sector functioning, to show various problem situations. At the same time, we can explore hidden trends in the development of the tourism sector. Therefore, it is important to use a variety of analysis methods to research tourism data. One of these methods is phase data analysis. This method is chosen for data analysis in the tourism industry.

\section{Related Works}

We have already noted that various methods and approaches can be used to analyze tourism data. The most common methods for analyzing data in the field of tourism are statistical analysis methods. A detailed review of various statistical analysis methods for exploring tourism data (Li, 2018). Among such methods, the methods of descriptive statistics, regression analysis, and cluster analysis are distinguished. At the same time, the authors note that data from the tourism sector is big data. Therefore, to analyze such data, it is necessary to highlight their common characteristics, and then it is necessary to select the appropriate analysis tools.

Copyright $\odot$ (2020, Journal of Asian Multicultural Research for Economy and Management Study, 
Use different statistical analysis methods to study data on different tourist flows (Li et al., 2020). In their research, the authors use cluster and classification analysis. This approach allows you to identify the same factors of influence on various tourist flows. This helps to understand the general mechanism of tourism sector development. Various statistical models to determine the individual classes in the structure of tourism expenditures (Ferrer et al., 2016). These models allow for segmentation of big data. To do this, the authors use models that are based on regression and cluster analysis.

At the same time use compositional analysis methods to analyze data in the tourism sector (Coenders \& Ferrer-Rosell, 2020). These methods are also based on standard statistical approaches. Analyze the possibility and feasibility of using various mathematical methods in the field of tourism (Shaidullina \& Ikhsanova, 2019). Among such methods, the authors investigate the methods of linear algebra, mathematical analysis, numerical analysis, and mathematical statistics. The paper shows that the choice of each method is determined by the conditions and the problem of data analysis in the field of tourism. Thus, we can say that different methods are used to analyze data from the tourism sector. It makes sense to use different analytical methods to research economic data. This is due to the fact that for such studies a whole arsenal of analysis methods is used (Kuzemin et al., 2005; Dobrovolskaya \& Lyashenko, 2013; Kuzemin \& Lyashenko, 2011; Lyashenko, 2014).

At the same time, it is important to understand that the dynamics of data describing economic processes can have different haracteristics. One of these characteristics is the uneven change in data in the time plane. Then the whole process can be characterized as nonlinear dynamics. The apparatus of the theory of phase analysis is used to study such dynamics. This apparatus is used in this work.

\section{Phase Portrait as a Phase Analysis Tool}

The key concept of nonlinear dynamics is the concept of a phase portrait of a statistical data series. In the phase space of dimension 2, using Cartesian coordinates, the phase portrait of a statistical data series in its simplest form is defined as a set of points:

$$
\Phi(C H R)=\left\{\left(g\left(r_{i}\right), g\left(r_{i+1}\right)\right)\right\}, i=\overline{1, t-1},
$$

where: $C H R$ is a series of statistical data that corresponds to a certain set; $g\left(r_{i}\right), g\left(r_{i+1}\right)-$ the values of the studied data series at certain time intervals $i=\overline{1, W}$, where $W$ is the length of the sought series.

A more complex method for constructing a phase portrait of a time series is to take into account the first and second derivatives of the original series. So if we have a certain series of statistical values of the $g\left(r_{i}\right)$, then its first and second derivatives can be found by the following formulas:

$$
\begin{gathered}
g^{\prime}\left(q_{j}\right)=g\left(r_{i+1}\right)-g\left(r_{i}\right) \\
g^{\prime \prime}\left(d_{c}\right)=g^{\prime}\left(q_{j+1}\right)-g^{\prime}\left(q_{j}\right)
\end{gathered}
$$

where: $g^{\prime}\left(q_{j}\right)$ - the values of the series of the first derivative of the original series $g\left(r_{i}\right)$, $j=\overline{1, W-1} ; g^{\prime \prime}\left(d_{c}\right)$ - the values of the series of the second derivative of the original series $g\left(r_{i}\right), c=\overline{1, W-2}$.

Then the required phase portrait is defined as a set of points: 


$$
\widetilde{\Phi}(C H R)=\left\{\left(g^{\prime}\left(q_{j}\right)\right),\left(q^{\prime \prime}\left(d_{c}\right)\right)\right\}, j=c=\overline{1, W-2},
$$

or

$$
\widetilde{\Phi}(C H R)=\left\{\left(g^{\prime}(t)\right),\left(g^{\prime \prime}(t)\right)\right\}, t=i,
$$

where: $t$-a time parameter that determines the change in the values of a series of statistical data.

\section{Data for Analysis}

Among the data that are characteristic of tourism activities are (Jahani et al., 2020): international tourism, expenditures, international tourism, expenditures for passenger transport items, international tourism, expenditures for travel items, international tourism, number of arrivals, international tourism, number of departures, international tourism, receipts, international tourism, receipts for passenger transport items, international tourism, receipts for travel items. These data refer to international tourism in general. Let's consider some data in more detail.Figure 1 shows the dynamics of the characteristics of international tourism expenditures (Figure 1a) and receipts from international tourism (Figure 1b).

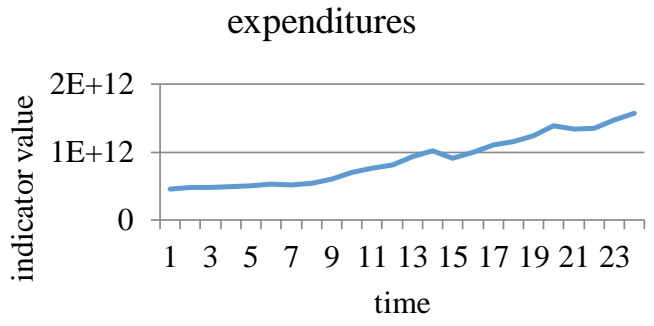

a)

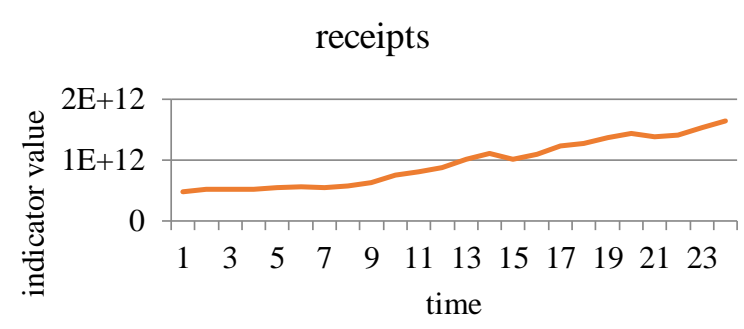

b)

Figure 1. Dynamics of expenditures on international tourism and receipts from international tourism

Figure 2 shows the dynamics of expenditures for passenger transport items (Figure 2a) and receipts for passenger transport items in terms of international tourism (Figure 2b).

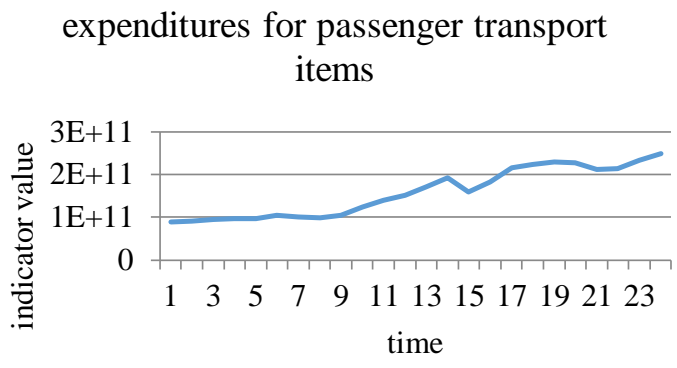

a) receipts for passenger transport items

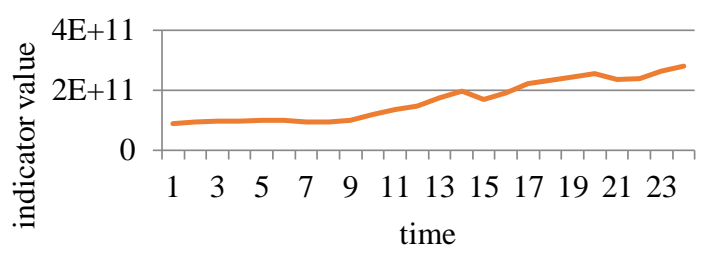

b)

Figure 2. Dynamics of expenditures for passenger transport items and receipts for passenger transport items in terms of international tourism

We see that the dynamics of the data in Figure 1a and Figure 1b, as well as Figure 2a and Figure $2 \mathrm{~b}$ are comparable. But we can also see some time intervals when there are non-linear 
changes in the dynamics of the processes that are being investigated. Therefore, we will conduct a more detailed analysis of the data.

\section{Results and Discussion}

Figure 3 shows the phase portraits of the dynamics of spending on international tourism (Figure 3a) and receipts from international tourism (Figure 3b).

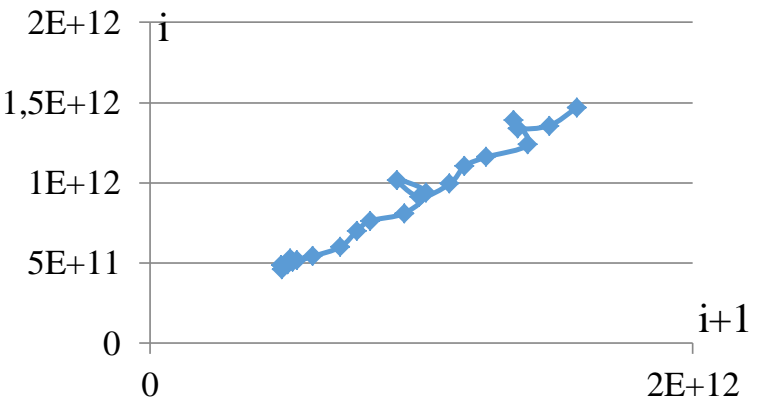

a)

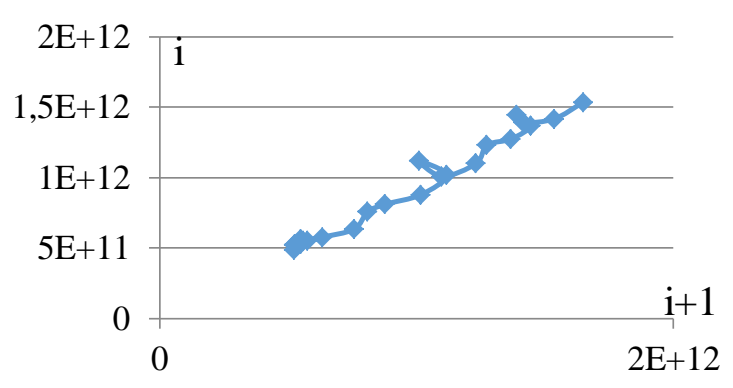

b)

Figure 3. Phase portraits of the dynamics of spending on international tourism and receipts from international tourism

It should be noted that the phase portraits presented in Figure 3 reflect the general dynamics of a positive trend in the change in the data of expenditures on international tourism and receipts from international tourism. Moreover, such dynamics can also be considered comparable. At the same time, we can observe some differences.

Figure 4 shows the phase portraits that reflect the rate of change in the dynamics of spending on international tourism (Figure 4a) and receipts from international tourism (Figure 4b).

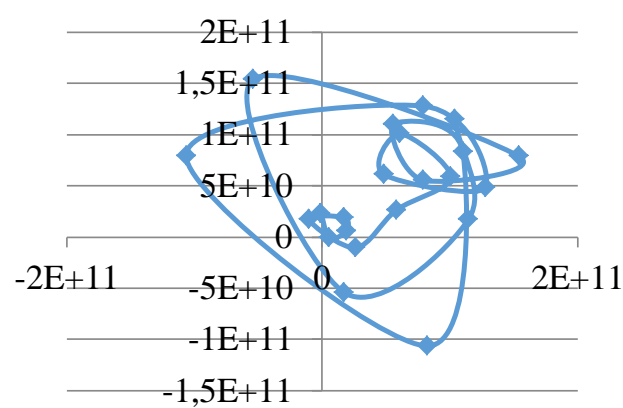

a)

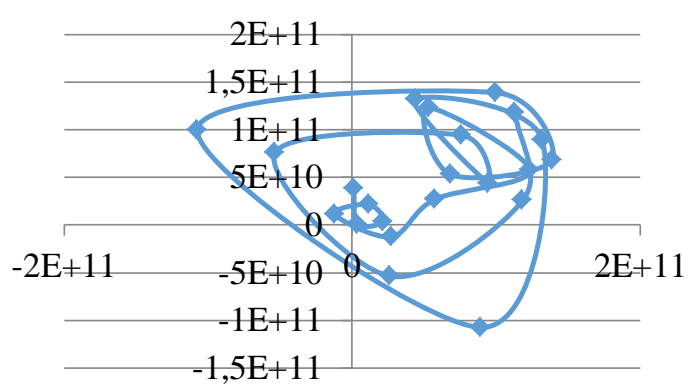

b)

Figure 4. Phase portraits that reflect the rate of change in the dynamics of spending on international tourism and receipts from international tourism

We see that the phase portraits of the rate of change in the dynamics of spending on international tourism and receipts from international tourism differ from each other. This difference is characterized by different quasi-cycles. At the same time, we can talk about the imbalance of the dynamics, which is reflected in the presented portraits. This fact underlines the nonlinearity of the data on the dynamics of expenditures on international tourism and receipts from international tourism. Such dynamics should be taken into account when predicting the development of processes in the tourism sector. Figure 5 shows phase portraits that reflect the rate of change in the dynamics of expenditures for passenger transport items (Figure 5a) and receipts for passenger transport items from the point of view of international tourism (Figure 5b). 


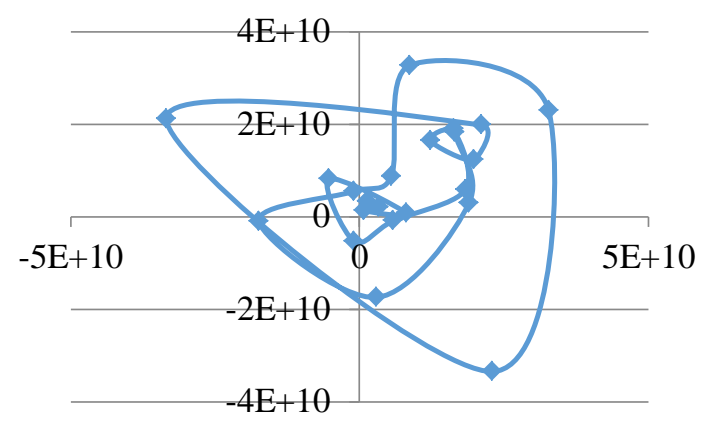

a)

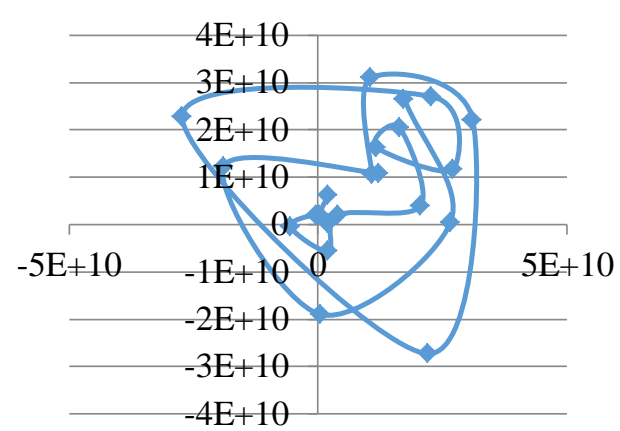

b)

Figure 5. Phase portraits that reflect the rate of change in the dynamics of expenditures for passenger transport items and receipts for passenger transport items from the point of view of international tourism

We see that the phase portraits of the rate of change in the dynamics of expenditures for passenger transport items and the rate of change in the dynamics of receipts for passenger transport items differ significantly from the point of view of international tourism. These differences are due to significant differences between the basic quasi-cycles between the data series that are being investigated. It should also be noted the imbalance between the dynamics of the data that we observe (see Figure 2). This suggests the need to take into account all the factors that affect the dynamics of processes in the tourism sector. This is important when making forecasts for the development of the tourism sector. It should also be noted that it was the influence of the dynamics of expenditures for passenger transport items and the rate of change in the dynamics of receipts for passenger transport items that influenced the dynamics of expenditures on international tourism and receipts from international tourism. This can be seen from the phase portraits, which show the rate of change of the corresponding data.

\section{Conclusion}

The paper discusses some issues of data analysis from the tourism sector. We have shown that different methods and approaches can be used to analyze data from the tourism sector. However, it should be taken into account that such data can represent nonlinear dynamics processes. Therefore, we used the phase analysis methodology. In particular, we used the concept of phase portrait to analyze data from the tourism industry. The paper shows that the data we processed have a non-linear relationship. This is important when making forecasts for the development of the tourism sector. The research results can be used to build information systems in the field of tourism industry regulation.

\section{References}

Akadiri, S. S., Alola, A. A., \& Uzuner, G. (2020). Economic policy uncertainty and tourism: evidence from the heterogeneous panel. Current Issues in Tourism, 23(20), 25072514.

Alimova, M. T., Abdusaidova, S. Y., \& Tuychiev, I. I. (2020). Innovative Directions of Tourism Development. Indonesian Journal of Cultural and Community Development, 7, 10-21070.

Baranova, V., Orlenko, O., Vitiuk, A., Yakimenko-Tereschenko, N., \& Lyashenko, V. (2020). Information System for Decision Support in the Field of Tourism Based on the Use of Spatio-Temporal Data Analysis. International Journal of Advanced Trends in Computer Science and Engineering, 9(4), 6356-6361. 
Butcher, J. (Ed.). (2019). Tourism, Cosmopolitanism and Global Citizenship. Routledge.

Coenders, G., \& Ferrer-Rosell, B. (2020). Compositional Data Analysis in Tourism: Review and Future Directions. Tourism Analysis, 25(1), 153-168.

Dobrovolskaya, I., \& Lyashenko, V. (2013). Interrelations of banking sectors of European economies as reflected in separate indicators of the dynamics of their cash flows influencing the formation of the resource potential of banks. European Applied Sciences, 1-2, 114-118.

Ferrer-Rosell, B., Coenders, G., \& Martínez-Garcia, E. (2016). Segmentation by tourist expenditure composition: an approach with compositional data analysis and latent classes. Tourism Analysis, 21(6), 589-602.

Hashimli, M. (2019). Azerbaijan's Tourism Sector-Opportunities and Obstacles. Available at SSRN 3485581.

Jahani, A., Goshtasb, H., \& Saffariha, M. (2020). Tourism impact assessment modeling of vegetation density for protected areas using data mining techniques. Land Degradation \& Development, 31(12), 1502-1519.

Kuzemin, A., \& Lyashenko V. (2011). Microsituation Concept in GMES Decision Support Systems. In Intelligent Data Processing in Global Monitoring for Environment and Security, 217-238.

Kuzemin, A., Lyashenko, V., Bulavina, E., \& Torojev, A. (2005). Analysis of movement of financial flows of economical agents as the basis for designing the system of economical security (general conception). In Third international conference «Information research, applications, and education, 27-30.

Li, D., Deng, L., \& Cai, Z. (2020). Statistical analysis of tourist flow in tourist spots based on big data platform and DA-HKRVM algorithms. Personal and Ubiquitous Computing, 24(1), 87-101.

Li, J., Xu, L., Tang, L., Wang, S., \& Li, L. (2018). Big data in tourism research: A literature review. Tourism Management, 68, 301-323.

Lyashenko, V. (2014). Efficiency of bank crediting of real sector of economy in the context of separate banking groups: an empirical example from Ukraine. International Journal of Accounting and Economics Studies, 2(2), 74-79.

McKercher, B., \& Mak, B. (2019). The impact of distance on international tourism demand. Tourism Management Perspectives, 31, 340-347.

Pencarelli, T. (2020). The digital revolution in the travel and tourism industry. Information Technology \& Tourism, 22(3), 455-476.

Shaidullina, R. M., \& Ikhsanova, F. A. (2019). Application of mathematical methods in consumer choice theory in tourism sphere. Revista ESPACIOS, 40(13), 1-6.

Xu, F., Nash, N., \& Whitmarsh, L. (2020). Big data or small data? A methodological review of sustainable tourism. Journal of Sustainable Tourism, 28(2), 144-163. 